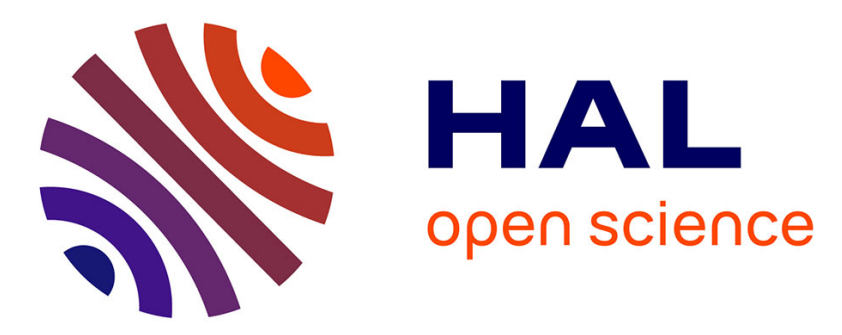

\title{
Fused Bis-lactams to Spirolactams: A New Member of the Family of Ring- Contraction Reaction
}

\author{
Guilhem Chaubet, Mathéo Berthet, Morgane Pasco, Guillaume Cazals, \\ Aurelien Lebrun, Jean Martinez, Isabelle Parrot
}

\section{- To cite this version: \\ Guilhem Chaubet, Mathéo Berthet, Morgane Pasco, Guillaume Cazals, Aurelien Lebrun, et al.. Fused Bis-lactams to Spirolactams: A New Member of the Family of Ring- Contraction Reaction. Letters in Organic Chemistry, 2018, 15 (12), pp.1046-1055. 10.2174/1570178615666180326160131 . hal- 02388789}

\author{
HAL Id: hal-02388789 \\ https://hal.science/hal-02388789
}

Submitted on 15 Dec 2020

HAL is a multi-disciplinary open access archive for the deposit and dissemination of scientific research documents, whether they are published or not. The documents may come from teaching and research institutions in France or abroad, or from public or private research centers.
L'archive ouverte pluridisciplinaire HAL, est destinée au dépôt et à la diffusion de documents scientifiques de niveau recherche, publiés ou non, émanant des établissements d'enseignement et de recherche français ou étrangers, des laboratoires publics ou privés. 


\title{
Fused Bis-lactams to Spirolactams: A New Member of the Family of Ring- Contraction Reaction
}

\author{
Guilhem Chaubet, Mathéo Berthet, Morgane Pasco, Guillaume Cazals, Aurélien Lebrun, \\ Jean Martinez and Isabelle Parrot ${ }^{*}$
}

Institut des Biomolécules Max Mousseron, IBMM UMR-5247 CNRS, Université de Montpellier, ENSCM, CC 17-03, PI.

E. Bataillon, 34095 Montpellier, Cedex 5, France

\section{ARTICLE HISTORY}

Received: December 12, 2017

Revised: January 26, 2017

Accepted: February 01, 2018

\begin{abstract}
A new ring contraction of fused bis-lactams into spirolactams is presented here. In the presence of a triflate catalyst in various solvents under microwave irradiation, this rearrangement allows a clean conversion of some fused bicycles into sp irocycles with good yields. The interest of this work thus lies in the use of activated 2,5-diketopiperazines as starting materials and demonstrates the wide range of applications of ring contraction reactions.
\end{abstract}

Keywords: Spirolactams, ring-contraction, heterocycles.

\section{INTRODUCTION}

For medicinal chemists, ring transformations or homologous variations in a cyclic series belong to essential rules of investigation on the structure-activity relationship. Being then a crucial tool for bioorganic chemists, ring-contraction reactions allow the facile modification of cyclic compounds, leading to structural analogues which could otherwise be difficult to access. Among these is the well-known Favorskii rearrangement which converts a-halocyclohexanones to cyclopentane derivatives under basic conditions [1]. Famous for over a century, this rearrangement can be classified as a carbocyclic ring-contraction [2-4], a class of reactions that has been overall intensely studied.

Analogously, heterocyclic ring-contraction reactions allow a pertinent access to a wide array of common scaffolds such as pyrroles [5, 6], iminosugars [7] oxetanes [8, 9] or thiiranes [10] being often a key step in the total synthesis of natural products [11]. In this context, our group has been focused on highlighting bis-Boc diketopiperazines (DKPs) as key reagents for the development of original ring-contraction reactions (Fig. 1). The specific reactivity induced by the presence of the two Boc groups in these bicyclic peptidic

structures was previously illustrated by two rearrangements occurring in basic media. In the presence of potassium hydroxide, bis-Boc DKPs are thus converted to hydantoins [12], while a stronger and less nucleophilic base, such as potassium tert-butoxide, promoted the selective production

${ }^{*}$ Address correspondence to Dr Isabelle Parrot at the Institut des Biomolécules Max Mousseron, IBMM UMR-5247 CNRS, Université de Montpellier, ENSCM, CC 17-03, PI. E. Bataillon, 34095 Montpellier Cedex 5, France; E-mail: isabelle.parrot-smietanne@umontpellier.fr of aminotetramates [13]. This Transannular Rearrangement of Activated Lactams (TRAL) offers convenient access to a useful reactive scaffold, which has been used to synthesize statins, pentacins, bicyclic lactams, and amino spirolactams $[14,15]$.

In this way, we described here our interest to the stereoselective conversion of aminotetramates to bis-lactams able to rearrange into spirolactams.

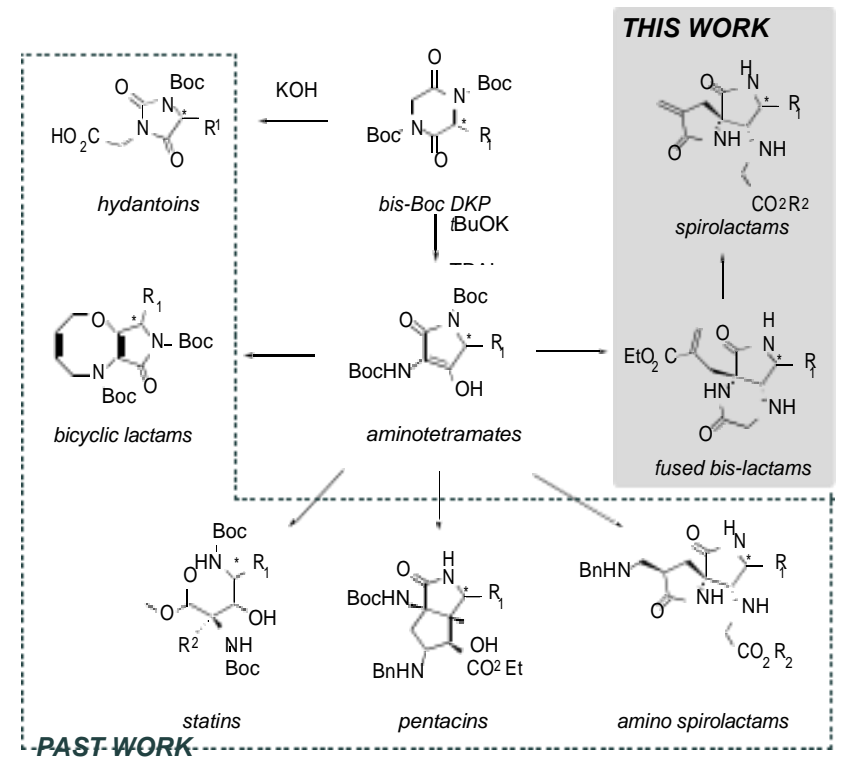

Fig. (1). Overview of ring-contraction reactions employing bis-Boc DKPs and their derivatives. 


\section{RESULTS AND DISCUSSION}

\subsection{Synthesis of Fused bis-lactams}

Starting from aminotetramate 1 , a diastereoselective tandem $O$-alkylation/Claisen rearrangement sequence led to pyrrolidine-dione 2 after a quantitative TFA deprotection of the Boc groups (Scheme 1). Coupling of the resulting primary amine with Boc-glycine delivered Boc-amino-ester 3a which was subsequently deprotected before undergoing intramolecular reductive amination. This reduction occurred with a complete diastereoselectivity, probably due to the steric hindrance of the iPr group and the lactam ring at both $\alpha$ and $\alpha^{\prime}$ positions, dictating the approach of the reducing agent to the Re face of the newly formed imine (not shown)".

This sequence to access bicyclic lactams 4 a proceeded with a good overall yield of $35 \%$ over 6 steps and, more importantly, with complete diastereoselectivity, leading to the creation of two novel stereogenic centers whose configurations were confirmed by X-ray crystallography [16].

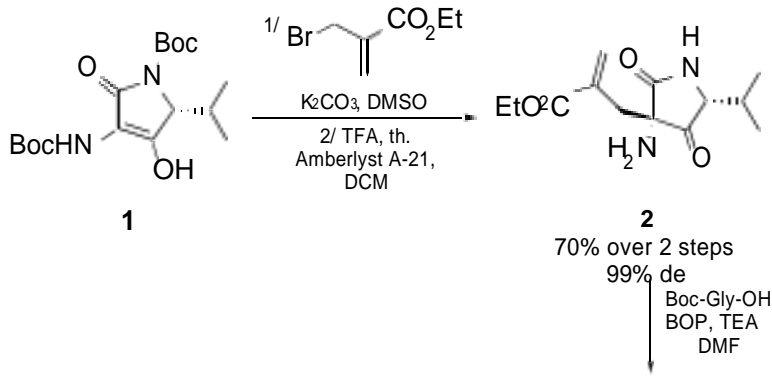

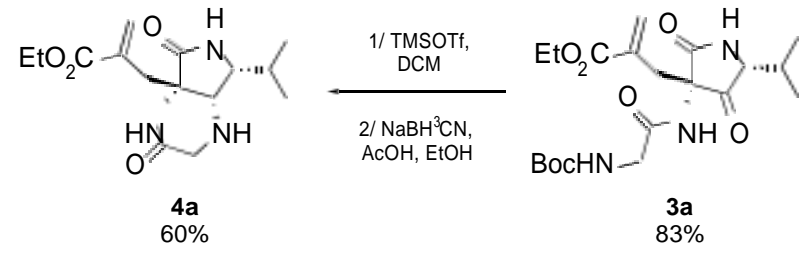

Scheme (1). Synthesis of fused bis-lactams ring systems.
Driven by these results, we next turned our attention to the synthesis of more complex bis-lactams by using chiral (L)-Boc-aminoacids instead of Boc-glycine (Table 1). However, the coupling of pyrrolidine-dione 2 with Boc-lysine resulted in a 1:1 mixture of diastereomers, presumably because of racemisation of the amino acid under the reaction conditions (BOP, NEt $)_{3}$ This was circumvented by replacing triethylamine with pyridine, resulting in the formation of diastereopure bicyclic precursors $\mathbf{3 b}$-f in decent yields. Then, the optimization of the preparation of bis-lactams, involving a stepwise imine formation/diastereoselective reduction, delivered the corresponding bis-lactams $\mathbf{4 b - f}$ with acceptable yields and lower reaction times.

\subsection{Ring-contraction of Fused bis-lactams}

With this small library of six bis-lactams $\mathbf{4 a - f}$ in hand, we turned our attention to their oligomerisation, hypothesizing that such oligomers could potentially display interesting foldamer properties, given the rigidity of their backbones. However, despite many attempts, the coupling between the secondary amine and the corresponding $\alpha, \beta$-unsaturated acid proved unsuccessful, presumably because of the steric hindrance around the amine. However, we were delighted to see that an original rearrangement occurred when bis-lactam $4 a$ was heated under microwave irradiation in the presence of an acid in absolute ethanol, leading to spirolactam 5 a (Table 2). To the best of our knowledge, such a rearrangement has not yet been reported, offering an interesting access to complex skeletons.

Among the different conditions screened to improve the yield of the ring contraction reaction of bicycle $4 \mathbf{a}$, we noticed an influence of the strength of the Brønsted acids (Table 2 , entries 1-4). While using acetic acid resulted in a moderate conversion, better conversion was observed with triflic acid. Switching to Lewis acids gave better yields in general, especially when employing zinc, manganese, magnesium or iron(II) triflates, while lanthanide triflates led to the decomposition of the starting material (Table 2, entries 5-7).

Table 1. Scope of the fused bis-lactams ring systems synthesis.

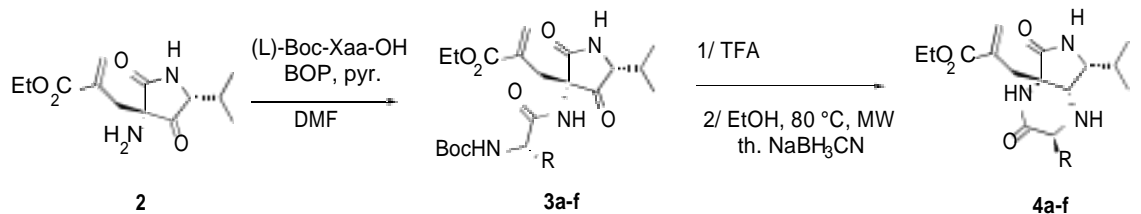

\begin{tabular}{|c|c|c|c|c|c|}
\hline Xaa & 3 & Yield (\%)a & 4 & Yield (\%)a & $t(h)$ \\
\hline Gly & $3 a$ & 82 & $4 a$ & 60 & 1.5 \\
\hline Asp(OBn) & $3 b$ & 70 & $4 b$ & 37 & 1.5 \\
\hline Phe & $3 c$ & 64 & $4 c$ & 63 & 1.5 \\
\hline $\operatorname{Ser}(B n)$ & $3 d$ & 60 & $4 d$ & 60 & 2 \\
\hline Lys(Z) & $3 e$ & 74 & $4 e$ & 53 & 1.5 \\
\hline $\operatorname{Dap}(Z)$ & $3 f$ & 60 & $4 f$ & 51 & 2.5 \\
\hline
\end{tabular}


Table 2. Screening of conditions for the fused bis-lactam to spirolactam ring-contraction reaction.

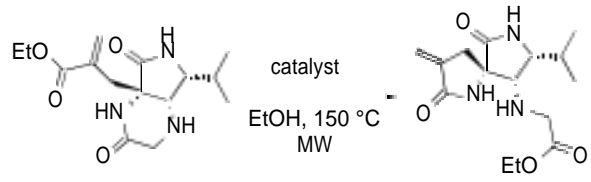

$4 a$

$5 a$

\begin{tabular}{|c|c|c|}
\hline Entry & Catalyst $^{a}$ & Yield (\%) ${ }^{b}$ \\
\hline 1 & $\mathrm{AcOH}$ & 5 \\
\hline 2 & TFA & 7 \\
\hline 3 & $\mathrm{H}_{2} \mathrm{SO}_{4}$ & 21 \\
\hline 4 & $\mathrm{TfOH}$ & 45 \\
\hline 5 & $\mathrm{Yb}(\mathrm{OTf})_{3}$ & Decomposition \\
\hline 6 & $\mathrm{Sm}(\mathrm{OTf})_{3}$ & Decomposition \\
\hline 7 & $\operatorname{Er}(\mathrm{OTf})_{3}$ & Decomposition \\
\hline 8 & $\mathrm{Mn}(\mathrm{OTf})_{2}$ & 55 \\
\hline 9 & $\mathrm{Fe}(\mathrm{OTf})_{2}$ & 55 \\
\hline 10 & $\mathrm{Mg}(\mathrm{OTf})_{2}$ & 55 \\
\hline 11 & $\mathrm{Zn}(\mathrm{OTf})_{2}$ & 55 \\
\hline 12 & Li(OTf) & 30 \\
\hline 13 & $\mathrm{Na}(\mathrm{OTf})$ & 5 \\
\hline 14 & $\mathrm{~K}(\mathrm{OTf})$ & 5 \\
\hline 15 & $\mathrm{Zn}\left(\mathrm{NTf}_{2}\right)_{2}$ & 55 \\
\hline 16 & $\mathrm{ZnO}$ & 10 \\
\hline 17 & $\mathrm{ZnCl}_{2}$ & 6 \\
\hline 18 & $\mathrm{Zn}(\mathrm{OTf})_{2}{ }^{\mathrm{c}}$ & 42 \\
\hline
\end{tabular}

aCatalyst loading $20 \mathrm{~mol} \%$, OYield of isolated product, Catalyst loading $10 \mathrm{~mol} \%$.

Interestingly, while triflic acid and lithium triflate gave acceptable conversions, both sodium and potassium triflates failed to catalyze the rearrangement (Table 2, entries 4, 1214). However, variations of the counteranion did not have a marked effect on certain metals' catalytic activities (see SI), which might demonstrate the coexistence of two catalytic cycles: one involving triflic acid and a second one involving the triflate salts. Moreover, the reaction proved to be reversible, as subjecting pure $\mathbf{5 a}$ to the reaction conditions led to the partial formation of $\mathbf{4 a}$ in similar ratios as before (determined by HPLC). As it was found to be the optimal loading, $20 \mathrm{~mol}$ $\%$ of zinc triflate was then used for studying the scope of the reaction. Water and other alcohol solvents - methanol, allyl alcohol, isopropanol and tert-butanol - were then screened (Table 3). Similar yields were obtained when ethanol, methanol or allyl alcohol was employed, with the spirolactams 5a-c being isolated as their corresponding esters (Table 3 , entries 1-3). It is worth mentioning that these reactions are extremely clean, resulting only in a mixture of spirolactam and transesterified starting material. The use of water as solvent delivered $49 \%$ of carboxylic acid $\mathbf{5} \mathbf{d}$ along with $50 \%$ of recovered starting material, with only traces of the hydrolysed bis-lactam $6 \mathbf{d}$ (Table 3 , entry 4 ). The steric bulk of the nucleophile revealed to be a crucial factor: employing tert-butanol resulted in no apparent conversion, whereas the use of isopropanol allowed the isolation of $65 \%$ of spirolactam $5 \mathbf{f}$ (Table 3, entries 5-6).

With these conditions in hand, we then focused our attention on the more challenging substituted bis-lactams $\mathbf{4 b - f}$. However, the presence of an extra substituent on the 6membered lactam seemed to prevent any rearrangement from occurring under our developed conditions, highlighting a fine balance in sterics between the substrates and the alcohol nucleophiles. Even in ethanol, amino-bearing bis-lactams $4 \mathrm{e}$ f proved unreactive, but bis-lactams $\mathbf{4 b}$ - $\mathbf{d}$ were converted to their corresponding spirolactams, although a yield could only be calculated for spirolactam $\mathbf{4 d}$.<smiles>CCOC(=O)C[C@]12NC(=O)C(COc3ccccc3)N[C@H]1C(C(C)C)NC2=O</smiles>

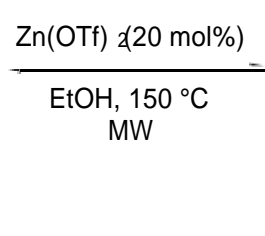<smiles>C=C(CC(NC(C)COCc1ccccc1)C(=O)OCC)C(=O)NC1C(=O)NC(C(C)C)C1C(=O)OCC</smiles>

Scheme (2). Application of the new fused to spiro rearrangement to more complex substrate.

\subsection{Suggested Mechanism}

A plausible mechanism for this new rearrangement is depicted in Scheme 3.

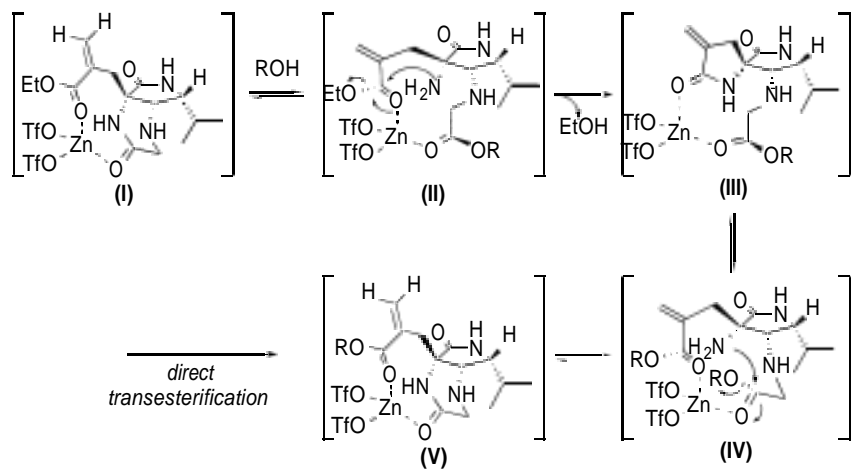

Scheme (3). Proposed mechanism for the bis-lactam to spiro rearrangement.

We postulate that activation of the two carbonyl groups by the zinc(II) species could result in ring-opening of the 6membered lactam by the nucleophilic alcohol to give the intermediate (II). A 5-exo-trig cyclisation would then lead to spirolactam (III), which could be in equilibrium with transesterified derivative $(\mathrm{V})$. When isopropanol is employed (R $=(\mathrm{Pr})$, the hindrance caused by the two isopropyl esters in 
Table 3. Solvent scope of the new fused bis-lactam to spirolactam ring-contraction reaction.

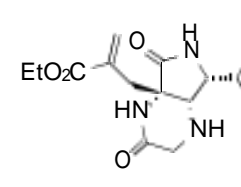

$4 a$

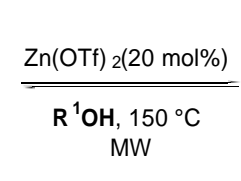

$\mathrm{MW}$

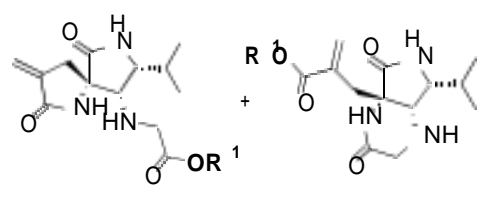

5
6

\begin{tabular}{|c|c|c|c|c|c|c|}
\hline Entry & $\mathbf{R}^{1}$ & 5 & Yield of $5(\%)^{a}$ & 6 & Yield of $6(\%)^{a}$ & Remaining $4 a$ \\
\hline 1 & -Et & $5 a$ & 55 & - & - & 45 \\
\hline 2 & $-\mathrm{Me}$ & $5 b$ & 55 & $6 b$ & 45 & 0 \\
\hline 3 & -Allyl & $5 c$ & 55 & $6 c$ & 45 & 0 \\
\hline 4 & $-H$ & $5 d$ & 49 & $6 d$ & $<5$ & 50 \\
\hline 5 & $-t-\mathrm{Bu}$ & $5 e$ & 0 & $6 e$ & 0 & 100 \\
\hline 6 & $-\operatorname{Pr}$ & $5 f$ & 65 & $6 f$ & 0 & 35 \\
\hline
\end{tabular}

aYield of isolated product.

the intermediate (IV) could prevent the 6-exo-trig cyclisation

from occurring, thus favoring the formation of spirolactam (III) instead of transesterified bis-lactam (V). However, direct transesterification of bis-lactam (I) to (V) cannot be ruled out either, even though this mechanism might only occur when non-hindered alcohols are used (Table 3 , entry 6 vs 2).

\section{CONCLUSION}

In conclusion, a synthesis of novel fused bis-lactam skeletons was developed. Some of those could be converted to spirolactams in the presence of zinc(II) triflate in a protic and nucleophilic solvent. This ring-contraction reaction represents an unusual and interesting reactivity, affording complex, and otherwise hard-to-access heterocyclic compounds.

\section{CONSENT FOR PUBLICATION}

Not applicable.

\section{CONFLICT OF INTEREST}

The authors declare no conflict of interest, financial or otherwise.

\section{ACKNOWLEDGEMENTS}

The authors thank the 'Ministère de l'Enseignement Supérieur et de la Recherche' and the CNRS for financial support.

\section{REFERENCES}

[1] Butkus, E. In Comprehensive Organic Synthesis II (Second Edition); Knochel, P., Ed.; Elsevier: Amsterdam, 2014; pp 853-886.

[2] Redmore, D.; Gutsche, C. D. In Advances in Alicyclic Chemistry; Hart, H., Karabatsos, G. J., Eds.; Elsevier, 1971; Vol. 3, pp 1-138.

[3] Hart, H.; Karabatsos, G. J. Advances in alicyclic chemistry. Volume 3 Volume 3; 1971.

[4] Silva, L. F. Tetrahedron 2002, 58 (45), 9137-9161.

[5] Joshi, U.; Pipelier, M.; Naud, S.; Dubreuil, D. Curr. Org. Chem. 2005, 9 (3), 261-288.

[6] L. Longridge, J.; W. Thompson, T. J Chem Soc C 2017, 16581661.

[7] Barnes, K. L.; Chen, K.; Catalano, V. J.; Jeffrey, C. S. Org. Chem. Front. 2015, 2 (5), 497-501.

[8] Jenkinson, S. F.; Fleet, G. W. J. Chimia 2011, 65 (1-2), 71-75.

[9] Morita, H.; Tatami, A.; Maeda, T.; Ju Kim, B.; Kawashima, W.; Yoshimura, T.; Abe, H.; Akasaka, T. J. Org. Chem. 2008, 73 (18), 7159-7163.

[10] Shiryaev, A.; Shiryaev, V.; Korlukov, A.; Khamitova, D. Synthesis 2011, 2011 (19), 3204-3207.

[11] Diethelm, S.; Carreira, E. M. J. Am. Chem. Soc. 2013, 135 (23), 8500-8503.

[12] Chaubet, G.; Cazals, G.; Lebrun, A.; Martinez, J.; Parrot, I. Synlett 2014, 25 (04), 574-578.

[13] Farran, D.; Parrot, I.; Martinez, J.; Dewynter, G. Angew. Chem. Int. Ed Engl. 2007, 46, 7488-7490.

[14] Farran, D.; Parrot, I.; Toupet, L.; Martinez, J.; Dewynter, G. Org. Biomol. Chem. 2008 , 6 (21), 3989-3996.

[15] Chaubet, G.; Coursindel, T.; Morelli, X.; Betzi, S.; Roche, P.; Guari, Y.; Lebrun, A.; Toupet, L.; Collette, Y.; Parrot, I.; Martinez, J. Org. Biomol. Chem. 2013, 11 (28), 4719-4726.

[16] Suitable crystals of the enantiomer of 4 a were obtained and analyzed by DRX (CCDC-654606) allowing us to deduce the configuration of $4 a$. 